\title{
Psychological Distress among Adults in Home Confinement in the Midst of COVID-19 Outbreak
}

\author{
Abhishek Lal ${ }^{1} \quad$ Anas Sanaullah¹ $\quad$ Mahnoor Khawaja M. Saleem ${ }^{1} \quad$ Naseer Ahmed $^{2,3} \quad$ Afsheen Maqsood ${ }^{4}$ \\ Naseer Ahmed ${ }^{5}$
}

${ }^{1}$ Department of Dental Surgery, Altamash Institute of Dental

Medicine, Karachi, Pakistan

${ }^{2}$ Department of Prosthodontics, Altamash Institute of Dental

Medicine, Karachi, Pakistan

${ }^{3}$ Prosthodontics Unit, School of Dental Sciences, University Sains

Malaysia, Kubang Kerian, Kelantan, Malaysia

${ }^{4}$ Department of Oral Pathology, Altamash Institute of Dental

Medicine, Karachi, Pakistan

${ }^{5}$ Department of Community Dentistry, Altamash Institute of Dental

Medicine, Karachi, Pakistan

Eur J Dent:2020;14(suppl S1):S27-S33

\author{
Address for correspondence Naseer Ahmed, BDS, FCPS, \\ Department of Prosthodontics, Altamash Institute of Dental \\ Medicine, Karachi 75500, Pakistan \\ (e-mail: naprosthodontist@gmail.com).
}

\begin{abstract}
Keywords

- COVID-19

- home confinement

- psychological distress

Objectives The aim of this study was to evaluate psychological distress caused by the novel coronavirus disease 2019 (COVID-19) pandemic among the adult population residing in Pakistan.

Materials and Methods This cross-sectional survey-based study comprised 1,000 adults residing in Pakistan. A questionnaire was formulated and circulated among adult population of Pakistan, the depression and anxiety symptoms using Patient Health Questionnaire-9 (PHQ-9) and Generalized Anxiety Disorder-7 (GAD-7) scales were assessed.

Statistical Analysis Independent $t$-test, cross tabulation, and regression analysis were used to identify variables having impact on PHQ-9 and GAD-7 scores. A p-value of $\leq 0.05$ was considered statistically significant.

Results Among 1,000 participants, 573 were males and 427 were females who completed the survey. Majority were restricted to home for more than 40 days. Considerable number of participants reported depressive $(540,54 \%)$ and anxiety (480, 48\%) symptoms. Gender, age, earnings, and occupation have significant relation with psychological distress, although similar was not found with education levels.

Conclusion Psychological distress, a concerning yet addressable issue was found among adults arising amid COVID-19 outbreak. Currently, physical health effects of COVID-19 are being looked, while mental health effects being under-addressed. This issue should be addressed to avoid any psychological impact in future.
\end{abstract}

\section{Introduction}

Since December 2019, coronavirus disease 2019 (COVID-19) emerged in Wuhan city of China and quickly disseminated across China, then later on as it is known today, throughout the globe. ${ }^{1}$ On March 11, 2020, the World Health Organization categorized coronavirus as pandemic, enforcing necessary guidelines to break the transmission cycle and minimize morbidities and mortalities. ${ }^{2}$

The emerging and remerging of these pathogens are always a challenge for global public health services affecting both individual as well as health care system levels. Although the possible origin of COVID-19 is still a debatable notion, possibility has been given to bats, which later on affected the
Dol https://doi.org/ 10.1055/s-0040-1718644 ISSN 1305-7456.

\footnotetext{
(C) 2020. European Journal of Dentistry.

This is an open access article published by Thieme under the terms of the Creative Commons Attribution-NonDerivative-NonCommercial-License, permitting copying and reproduction so long as the original work is given appropriate credit. Contents may not be used for commercial purposes, or adapted, remixed, transformed or built upon. (https://creativecommons.org/licenses/by-nc-nd/4.0/)

Thieme Medical and Scientific Publishers Pvt. Ltd., A-12, 2nd Floor, Sector 2, Noida-201301 UP, India
} 
mammalian hosts. ${ }^{3}$ Furthermore, previous outbreak of Middle East respiratory syndrome and severe acute respiratory syndrome (SARS) has also proved to be a difficult confrontation for the public health authorities and health care workers. ${ }^{4}$

Regarding transmission of coronavirus, the primary route has been through direct human to human close contact via respiratory droplets. ${ }^{5,6}$ Due to this, global health communities in collaboration with government authorities decided to impose lockdown to promote social distancing, hence hindering the transmission cycle of this virus. The initial incubation period of the infected person has been noted to be anywhere between 2 and 14 days, which may vary. ${ }^{7,8}$ Symptomatic patients mainly present with fever, dry cough, sore throat, myalgia, and later on shortness of breath, with disturbed smell sensation and stomach upset seen in some patients. ${ }^{9,10}$ Moreover, these symptoms may tend to worsen with time or some patients may not even present with any symptoms and yet still be COVID-19 positive. ${ }^{11,12}$ The latter scenario is more problematic for the health care community because these asymptomatic individuals tend to circulate the virus around themselves without knowing it. Different age groups in the society may have different susceptibility as well as fatalities rates when affected by the novel coronavirus.

Additionally, elderlies and those with underlying comorbidities such as hypertension, diabetes, chronic respiratory ailment, and immunosuppression are known to contract the virus more readily as well as may even suffer a severe infection. ${ }^{13,14}$ Habit such as smoking is also associated with negative progression as well as adverse outcomes in a patient suffering from COVID-19. ${ }^{15}$ Although all age groups are susceptible to contracting the virus, young healthy individuals are less likely to contract the virus as well as to suffer from severe infection as compared with the elderlies and those with comorbidities. ${ }^{16}$

Throughout the globe, countries have imposed lockdown of different criteria mainly focusing on social distancing as individuals are not allowed to leave their house unless it is necessary. This has led to home confinement of the general population which has been previously unknown in generality. These massive quarantine measures imposed by the authorities have led to common mental health problems such as anxiety and depression along with fear of contracting COVID-19 as well as being in close contact with anyone. Moreover, individuals are handling this home confinement differently with mental health status or psychological distress being a concern. Besides all these points, the current generation is not accustomed to handle such social distancing protocols primarily due to increased number of social activities and gatherings, therefore, perceiving it as home imprisonment. Additionally, the idea of home confinement perceived as imprisonment wrecks a havoc among all of the population, but young adults experience greater social gatherings as compared with middle-aged and older adults, hence the younger adults are more prone to develop psychological distress.

Economical downfall has led to earning deficit on both employers as well as employees, hence delay in wages. Unemployment amidst COVID-19 outbreak is another contributing factor which may lead to uneasiness and a constant fear.
The temperamental nature of this pandemic has been amplified by myths and misleading information, often driven by counterfactual news reports and the population's wrong understanding of the health care messages, thus generating more worry.

This study has aimed to provide an assessment of the psychological distress among the adult population residing in Pakistan facing home confinement ever since the lockdown was imposed officially by the government. Risk factors that may exacerbate mental uneasiness of the adult population have been addressed in this study such as age, gender, level of education, province, and socioeconomic status.

The rationale of our study is to evaluate the psychological impact of COVID-19 on adults in home confinement. Evaluating it might prevent any negative outcomes inflicted by this pandemic in future. Therefore, this investigation might aid in providing counseling and treatment plans for those who are affected. Furthermore, similar studies have been conducted assessing similar aims to our study. ${ }^{17,18}$

\section{Materials and Methods}

In Pakistan, general population was restricted to home starting from March 23, 2020, marking the beginning of official lockdown and was allowed to visit outside only on necessary basis as stated by the government. A well-structured questionnaire consisted of closed-ended questions was constructed. The questionnaire was uploaded to Google forms and an online link was created. OpenEpi sample size calculator was used to calculate the sample size of this study with the participants' response rate of 178,417 and desired percentile of 50. Keeping the confidence interval of $95 \%$ and $\alpha$ error of $5 \%$, the total sample size calculated was 1,000 participants.

The simple random sampling technique was applied in this study. The participants were invited to join through short messaging services. Those who accepted to participate were formally requested to fill a well-structured online questionnaire through different social media platforms such as WhatsApp, Instagram, Facebook messenger, Viber, Zalo, Telegram, and e-mails by direct sharing of the online link. Consent statement was included in the questionnaire for voluntary participation and response was recorded. The study included adult population only residing in different provinces of Pakistan currently being under lockdown situation. Children and adolescents were excluded from this study. The participants were anonymous, and their information were kept confidential. Ethics and review committee of Altamash Institute of Dental Medicine (AIDM) approved this study (AIDM/EC/04/2020/01).

The questionnaire was focused on symptoms of anxiety and depression using validated measurement tools. ${ }^{19,20}$ Section 1 included information regarding demographic data which includes age group, gender, location, level of education, occupation, earnings, and general questions regarding optimism about the current pandemic and if worried about being infected by COVID-19 was also part of this questionnaire.

Section 2 comprised specific questions on depressive and anxiety symptoms using Patient Health Questionnaire-919 
(PHQ-9) and Generalized Anxiety Disorder-7 (GAD-7) scales, ${ }^{20}$ respectively. Each question in both scales denotes four options as follows: $0=$ not at all, $1=$ several days, $2=$ more than half the days, and $3=$ nearly every day. Each option had its own numerical value to provide total score at the end.

The total mean scores were interpreted as PHQ-9, normal (0-4), mild (5-9), moderate (10-14), moderately severe (15-19), and severe (20-27) depression and GAD-7, normal (0-4), mild (5-9), moderate (10-14), and severe (15-21) anxiety. All these questions were formulated in the questionnaire and made in English language.

The data analysis was performed on SPSS statistical software version 25 . The $p$-value of $\leq 0.05$ was considered as statistically significant. Descriptive statistics was used to determine frequency, percentages, mean, and standard deviation of the quantitative and qualitative variables. Furthermore, to analyze confounders, any relation of age, gender, earnings, education, and occupation with PHQ-9 and GAD-7 scores, independent $t$-test, cross tabulation, and regression analysis tests were performed.

\section{Results}

In this study, a total of 1,080 filled questionnaires were received after scrutiny; 80 forms were excluded on the basis of irrelevance and partially filled forms. The response rate of the participants was $92.59 \%$. The internal consistency of items in questionnaire was tested by intraclass correlation with a strong relation of 0.85 .

As presented in - Table 1, of the 1,000 participants, majority were males and belonged to 18 to 30 years age group. Predominantly, individuals had undergraduate and graduate levels of education. Students, business, health care workers, and engineers were most selected occupation of the participants. Furthermore, more than one-third participants believed that their earning is affected during COVID-19. Moreover, in our study, majority of subjects were currently unemployed during this pandemic. While two-third of participants were confined to home for more than 40 days and worried during the current COVID-19 outbreak but with a strong believed that normal situation will be restored soon (-Table 2). The main characteristics of PHQ-9 and GAD-7 scales are described in - Table 3.

In our study, the PHQ-9 scores of the 1,000 adults fall in the following categories for depression: none, 460; mild, 254; moderate, 165; moderately severe, 74 ; severe, 47 and GAD-7 categories for anxiety: none, 520; mild, 284; moderate, 139 ; severe, 57 . A considerable number of participants reported to have depressive $(540,54 \%)$ and anxiety (480, 48\%) symptoms, with females responding with more depressive $(611,61.1 \%)$ as well as anxiety $(532,53.2 \%)$ symptoms as compared with males. Considering age group, participants belonging to the age group of 18 to 30 years divulged to suffer from more anxiety $(522,52.2 \%)$ as well as depressive $(611,61 \%)$ symptoms with increasing age leading to less anxiety as well as depressive symptoms among adults. In view of level of education, it was found that adults
Table 1 Demographic characteristics of participants $(N=1,000)$

\begin{tabular}{|l|l|}
\hline Variables & $\boldsymbol{n}(\%)$ \\
\hline Age, y & $569(56.9)$ \\
\hline $18-30$ & $210(21.0)$ \\
\hline $31-40$ & $102(10.2)$ \\
\hline $41-50$ & $61(6.1)$ \\
\hline $51-60$ & $58(5.8)$ \\
\hline Above 60 & $375(37.5)$ \\
\hline Education & $346(34.6)$ \\
\hline Undergraduate & $187(18.7)$ \\
\hline Graduate & $92(9.2)$ \\
\hline Postgraduate & $178(17.8)$ \\
\hline Below undergraduate & $139(13.9)$ \\
\hline Occupation & $108(10.8)$ \\
\hline Business & $327(32.7)$ \\
\hline Health care worker & $15(1.5)$ \\
\hline Engineer & $96(9.6)$ \\
\hline Student & $137(13.7)$ \\
\hline Labor work & $527(42.7)$ \\
\hline Unemployed & \\
\hline Others & \\
\hline Gender & \\
\hline Male & \\
\hline Female & $(57.3)$ \\
\hline Province & \\
\hline Sindh & \\
\hline Punjab & \\
\hline Baluchistan & \\
\hline Khyber Pakhtunkhwa & \\
\hline
\end{tabular}

having undergraduate and postgraduate educational backgrounds had most anxiety ( $489,48.9 \%$ and $530,53 \%$, respectively) and depressive (570,57\% and $670,67 \%$, respectively) symptoms in comparison to those belonging to graduate and below undergraduate educational levels. Labor workers had the highest anxiety $(930,93 \%)$ and depressive $(870,87 \%)$ symptoms. The students, health care workers, and those currently unemployed individuals report similar symptoms. Furthermore, those earning above Rs. 50,000 had less anxiety $(400,40 \%)$ and depressive $(460,46 \%)$ symptoms as compared with ones earning below Rs. 50,000.

The mean value of PHQ-9 and GAD-7 were 6.91 and 6.14, respectively, which falls in mild psychological distress category as described in - Table 4 . As far as the effect of gender is concerned, we noted a significant difference PHQ-9 $(p=<0.00)$ and GAD-7 $(p=0.03)$ between the responses of two scales. Additionally, in our study, the participants belonged to the mean age bracket of 18 to 30 years and when the effect age was compared with GAD-7 and PHQ-9 scores, we found a significant difference $(p=0.001)$ 
Table 2 Responses pertaining to home confinement and financial situation of participants $(N=1,000)$

\begin{tabular}{|c|c|}
\hline Variables & $n(\%)$ \\
\hline \multicolumn{2}{|c|}{ You are in confinement from how many days? } \\
\hline $1-10 d$ & $59(5.9)$ \\
\hline $11-20 d$ & $56(5.6)$ \\
\hline $21-30 \mathrm{~d}$ & $76(7.6)$ \\
\hline $31-40 d$ & $157(15.7)$ \\
\hline More than $40 \mathrm{~d}$ & $652(65.2)$ \\
\hline \multicolumn{2}{|c|}{ Do you think the normality will be restored nearly? } \\
\hline Yes & $511(51.1)$ \\
\hline No & $199(19.9)$ \\
\hline Do not know & $290(29.0)$ \\
\hline \multicolumn{2}{|c|}{ Does COVID-19 affect your earning? } \\
\hline Yes & $424(42.4)$ \\
\hline No & $491(49.1)$ \\
\hline Maybe & $85(8.5)$ \\
\hline \multicolumn{2}{|l|}{ What is your current earning? } \\
\hline Rs. $10,000-20,000$ & $40(4.0)$ \\
\hline Under Rs. 10,000 & $50(5.0)$ \\
\hline Rs. $20,000-30,000$ & $64(6.4)$ \\
\hline Rs. $30,000-40,000$ & $79(7.9)$ \\
\hline Rs. $40,000-50,000$ & $101(10.1)$ \\
\hline Above Rs. 50,000 & $228(22.8)$ \\
\hline Currently unemployed & $438(43.8)$ \\
\hline \multicolumn{2}{|c|}{ Are you worried about current financial situation? } \\
\hline To a large extent & $42(4.2)$ \\
\hline To a moderate extent & $329(32.9)$ \\
\hline To a little extent & $453(45.3)$ \\
\hline Not at all & $176(17.6)$ \\
\hline \multicolumn{2}{|c|}{ Does COVID-19 affect your earning? } \\
\hline Yes & $424(42.4)$ \\
\hline No & $491(49.1)$ \\
\hline Maybe & $85(8.5)$ \\
\hline
\end{tabular}

Abbreviation: COVID-19, coronavirus disease 2019.

and $(p=0.004)$, respectively, among the participants as described in - Table 3.

The linear regression analysis revealed a significant association of occupation, current earnings, and earnings affected during outbreak with GAD-7 and PHQ-9 mean scores amid COVID-19 pandemic as presented in - Table 5. However, there was no significant difference between education levels and psychological distress.

\section{Discussion}

This cross-sectional study had enrolled 1,000 participants, unraveling $54 \%$ of the adult population reporting depressive symptoms and $48 \%$ with anxiety symptoms. Most participants were males. To conclude, our study reported that female gender experienced more depressive and anxiety symptoms as compared with males which could be due to increased work burden alongside being confined to home. ${ }^{21}$ Female gender is further affected mentally and being overburdened physically by looking after their children and family. Additionally, parents are further stressed by children staying at home, since their future remains uncertain due to closure of schools, colleges, and universities as part of lockdown currently imposed.

Most of the participants in our study belonged to 18 to 30 years age group and this age group responded with highest depressive and anxiety scores in comparison with other age groups. Young adults as found in our study are suffering more anxiety and depressive symptoms. One of the reasons could be that this age group participates more in social activities, making home confinement for long periods of time a mental havoc. On one hand, elderly in our study reported to experience less depressive and anxiety symptoms, and on the other hand, the literature states elderlies do experience it especially during COVID-19 outbreak. 22,23 This can be due to higher maturity and more understanding nature with regard to the current situation.

Adult populations are involved in various occupations in Pakistan. We deduced in our study that students, labor workers, health care workers, and unemployed individuals reported higher anxiety and depressive scores. Unemployment among daily wage earners especially labor workers is a major concern. Socioeconomic factor has been of significant importance in adult's mental well-being. Primary mode of transmission of COVID-19 is direct human to human because health care workers work in close approximation with patients, this generates further worry among close family members in home confinement due to increased risk of contracting the virus. ${ }^{24}$ In students mainly belonging to young adults age group, unaccustomed to be in home confinement, this creates mental health disturbance symptoms. Moreover, companies have been cutting short their employers count due to current financial crises of the country, so unable to cope up during these tough times is a further contributing factor.

COVID-19 has taken a heavy toll on economic pillar of different countries. Low- and middle-income countries such as Pakistan have health care systems not being well established to cater such challenges. ${ }^{25}$ Countries ranking in low gross domestic product (GDP) categories have been affected more substantially as compared with those belonging to high GDP rankings. In addition to this, those with high GDP can economically compensate their residents so as to reduce financial as well as mental stress. Losing jobs as well as salary reduction make matters worse for individual's family especially when they are the lone earner in a family of multiple dependents. As the adult's monthly earnings decreased from Rs. 50,000 to Rs. 10,000, more depressive and anxiety symptoms presented among them. Additionally, it has been reported that hoarding of personal protective equipment has made availability as well as cost of these a major hurdle to protect oneself, generating further anxiety and depression. ${ }^{26}$ Furthermore, shortage of basic personal necessities due to its hoarding 
Table 3 Characteristics of PHQ-9 and GAD-7 scales $(N=1,000)$

\begin{tabular}{|c|c|c|c|c|c|}
\hline & & Not at all, \% & Several days, \% & $\begin{array}{l}\text { More than half } \\
\text { the days, } \%\end{array}$ & $\begin{array}{l}\text { Nearly } \\
\text { everyday, \% }\end{array}$ \\
\hline \multicolumn{6}{|c|}{ PHQ-9 scale } \\
\hline PHQ-1 & $\begin{array}{l}\text { Little interest or pleasure in doing } \\
\text { things }\end{array}$ & 33.1 & 44.4 & 11.3 & 11.2 \\
\hline PHQ-2 & $\begin{array}{l}\text { Feeling down, depressed, or } \\
\text { hopeless }\end{array}$ & 32.1 & 46.8 & 11.1 & 10.0 \\
\hline PHQ-3 & $\begin{array}{l}\text { Trouble falling or staying sleep or } \\
\text { sleeping too much }\end{array}$ & 43.4 & 31.7 & 11.4 & 13.5 \\
\hline PHQ-4 & $\begin{array}{l}\text { Feeling tired or having low } \\
\text { energy }\end{array}$ & 40.8 & 35.6 & 12.9 & 10.7 \\
\hline PHQ-5 & Poor appetite or overeating & 52.3 & 27.3 & 11.5 & 8.9 \\
\hline PHQ-6 & Feeling bad about yourself & 64.1 & 20.1 & 7.8 & 8.0 \\
\hline PHQ-7 & Trouble concentrating on things & 58.8 & 21.8 & 10.3 & 9.1 \\
\hline PHQ-8 & Moving or speaking slowly & 65.7 & 20.7 & 9.2 & 4.4 \\
\hline PHQ-9 & Thoughts about hurting yourself & 71.7 & 16.4 & 7.5 & 4.4 \\
\hline \multicolumn{6}{|c|}{ GAD-7 scale } \\
\hline GAD-1 & Feeling nervous, anxious & 36.4 & 45.2 & 12.7 & 5.7 \\
\hline GAD-2 & $\begin{array}{l}\text { Not being able to stop or control } \\
\text { worrying }\end{array}$ & 35.8 & 41.5 & 13.5 & 9.2 \\
\hline GAD-3 & Worrying too much & 30.3 & 44.8 & 15.1 & 9.8 \\
\hline GAD-4 & Trouble relaxing & 49.1 & 31.1 & 12.1 & 7.7 \\
\hline GAD-5 & Being restless & 52.9 & 29.9 & 10.3 & 6.9 \\
\hline GAD-6 & Being easily annoyed or irritable & 45.7 & 32.0 & 11.8 & 10.5 \\
\hline GAD-7 & $\begin{array}{l}\text { Feeling something awful might } \\
\text { happen }\end{array}$ & 43.1 & 34.1 & 12.5 & 10.3 \\
\hline
\end{tabular}

Abbreviations: GAD, Generalized Anxiety Disorder; PHQ, Patient Health Questionnaire.

Table 4 Effect of gender and age groups on PHQ-9 and GAD-7 scales $(N=1,000)$

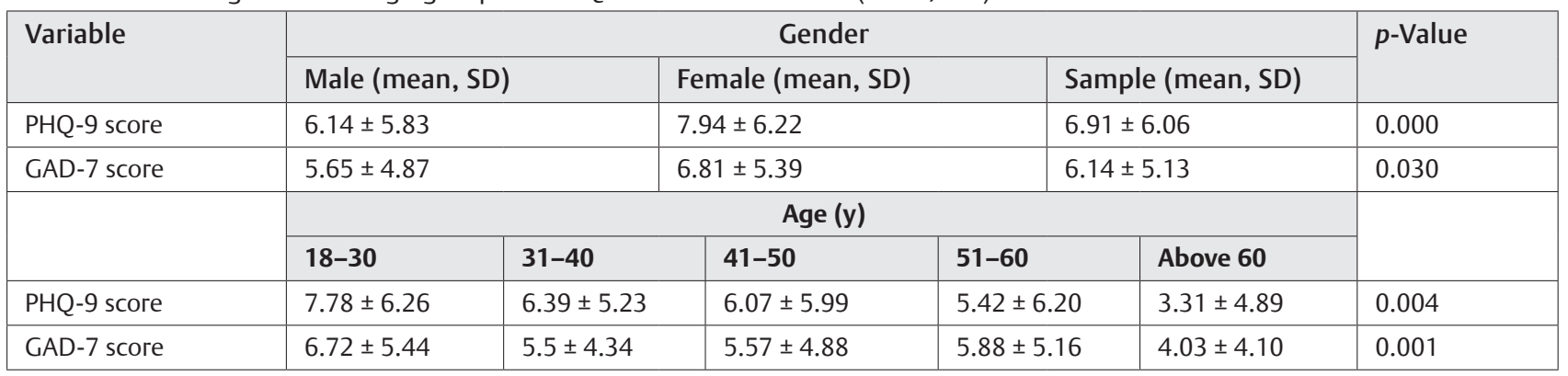

Abbreviations: GAD, Generalized Anxiety Disorder; PHQ, Patient Health Questionnaire; SD, standard deviation.

is another contributing factor to generate stress among the population. ${ }^{27}$ Many people have also initiated the practice of "panic buying" large stocks of basic necessities in the midst of this outbreak. ${ }^{28}$

Various information regarding coronavirus pandemic are available on different platforms, although its creditability is questionable. Moreover, misinformation regarding the coronavirus pandemic has been known to generate mental health disturbances. ${ }^{29}$ Overwhelming flow of headline news as well as images and videos regarding COVID-19 and its infectives can be a stress boosting factor. Majority of the adults are worried regarding the current circumstances, but they are remaining optimistic hoping that situation will resolve. Although current literature states varying information on when the pandemic will end, the previous pandemic, Spanish flu, 100 years ago, lasted for 2 years which can act as a predictor for the COVID-19 pandemic. ${ }^{30}$

Psychological distress is a worrying notion these days since the beginning of this pandemic. In literature, it is reported that various countries are implementing protocols by forming authorities that are responsible to cater individual's mental health problems, although we found no such authorities working here. ${ }^{31}$ This can be due to bigger dilemmas being faced by authorities here such as economic burdens and implementing protection protocols against COVID-19. 
Table 5 Linear regression of financial, occupation, and education levels amid COVID-19 outbreak and its psychological impact during home confinement $(N=1,000)$

\begin{tabular}{|c|c|c|c|c|c|c|c|c|c|c|}
\hline \multirow{2}{*}{$\begin{array}{l}\text { Acronym } \\
\text { of study } \\
\text { scales }\end{array}$} & \multirow[t]{2}{*}{ Variables } & \multicolumn{2}{|c|}{$\begin{array}{l}\text { Unstandardized } \\
\text { coefficients }\end{array}$} & \multirow[t]{2}{*}{$\begin{array}{l}\text { Standardized } \\
\text { coefficients beta }\end{array}$} & \multirow[t]{2}{*}{$t$} & \multirow[t]{2}{*}{$p$-Value } & \multicolumn{2}{|c|}{$\begin{array}{l}95 \% \text { confidence } \\
\text { interval for } B\end{array}$} & \multicolumn{2}{|c|}{ Collinearity } \\
\hline & & $B$ & $\begin{array}{l}\text { Std. } \\
\text { error }\end{array}$ & & & & $\begin{array}{l}\text { Lower } \\
\text { bound }\end{array}$ & $\begin{array}{l}\text { Upper } \\
\text { bound }\end{array}$ & Tolerance & VIF \\
\hline \multirow[t]{4}{*}{ PHQ-9 } & Education & -0.353 & 0.196 & -0.056 & -1.795 & 0.073 & -0.738 & 0.033 & 0.970 & 1.031 \\
\hline & Occupation & 0.414 & 0.099 & 0.133 & 4.173 & $0.000^{\mathrm{a}}$ & 0.219 & 0.609 & 0.928 & 1.078 \\
\hline & Current earnings & -0.667 & 0.113 & -0.193 & -5.931 & $0.000^{\mathrm{a}}$ & -0.888 & -0.447 & 0.898 & 1.113 \\
\hline & $\begin{array}{l}\text { COVID-19 affected } \\
\text { earnings }\end{array}$ & -0.798 & 0.318 & -0.083 & -2.508 & $0.012^{\mathrm{b}}$ & -1.422 & -0.173 & 0.872 & 1.146 \\
\hline \multirow[t]{4}{*}{ GAD-7 } & Education & -0.349 & 0.167 & -0.066 & -2.091 & $0.037^{\mathrm{b}}$ & -0.677 & -0.021 & 0.970 & 1.031 \\
\hline & Occupation & 0.190 & 0.084 & 0.072 & 2.253 & $0.024^{b}$ & 0.025 & 0.356 & 0.928 & 1.078 \\
\hline & Current earnings & -0.509 & 0.096 & -0.173 & -5.317 & $0.000^{\mathrm{a}}$ & -0.697 & -0.321 & 0.898 & 1.113 \\
\hline & $\begin{array}{l}\text { COVID-19 affected } \\
\text { earnings }\end{array}$ & -0.773 & 0.271 & -0.095 & -2.855 & $0.004^{b}$ & -1.304 & -0.242 & 0.872 & 1.146 \\
\hline
\end{tabular}

Abbreviations: $B$, the rate of change per unit between dependent and independent variables; COVID-19, coronavirus disease 2019; GAD, Generalized Anxiety Disorder; PHQ, Patient Heath Questionnaire; Std., standard deviation; $t$, test of the regression coefficients; VIF, variance inflation factor, denotes the amount of multicollinearity in model.

Notes: Beta denotes the correlation between variables. For PHQ-9, the constant for R-squared $\left(R^{2}\right)=0.058$ and adjusted R-squared $\left(A R^{2}\right)$ was 0.055 , while for GAD-7, $R^{2}=0.048$ and $A R^{2}$ was 0.044 .

${ }^{a}$-Value $<0.001$.

${ }^{\mathrm{b}} \mathrm{p}$-Value $<0.05$.

We have deduced that coronavirus pandemic has a major impact on mental health of adults. Literature states individuals have started avoidance behavior regarding social gathering as well as maintaining strict hygiene measures. ${ }^{32}$ Adults are currently experiencing fear of contracting the virus as well as boredom, health changes, loneliness, and anger during these tough times. ${ }^{33,34}$ Mandatory tracing of contacts of COVID-19 positive patient's friends and relatives as well as undergoing 14 days of quarantine has enhanced already present stress. ${ }^{33}$

In accordance with Xiang et al, mental health care needs to be timely managed to prevent psychological impact on one's life. ${ }^{35}$ Previously, during 2003 SARS outbreak, similar conditions have been reported as currently being experienced. ${ }^{36}$ So far mental health of the general population as well as the patients suffering from COVID-19 seems to be under-addressed.

We evaluated psychological impact of COVID-19 in adults and found some limitations. First, this study can be conducted between adults of different countries which can provide better results and comparison regarding mental health status as home confinement is being performed globally. Finally, inclusion of children and adolescents can increase the scope of assessing psychological impact since mental health disturbance is also found in this age group. Avoiding these limitations can aid in further studies being carried on.

\section{Conclusion}

To conclude, COVID-19 pandemic does have a psychological impact on the adult population in home confinement, although education levels have no significant association with psychological distress. This study proposed that mental health disturbance is a concerning yet addressable issue if proper measures are instituted. Special interventions to encourage mental health support in adults need immediate implementation to avoid any potential psychological impact of the current situation in the future.

Funding

None.

\section{Conflict of Interest}

None declared.

\section{Acknowledgments}

The authors thank all the participants involved in this study for their collaboration and support. Also, grateful to ethical review committee of Altamash Institute of Dental Medicine, Pakistan and School of Dental Sciences, Health Campus, University Sains Malaysia for help and assistance in this study.

\section{References}

1 Li Q, Guan X, Wu P, et al. Early transmission dynamics in Wuhan, China, of novel coronavirus-infected pneumonia. N Engl J Med 2020;382(13):1199-1207

2 WHO Director-General's opening remarks at the media briefing on COVID-19, March 11, 2020. World Health Organization website. Updated March 11, 2020. Available at: https://www. who.int/dg/speeches/detail/who-director-general-s-openingremarks-at-the-media-briefing-on-covid-19-11-march-2020. Accessed May 21, 2020

3 Zhou P, Yang X-L, Wang X-G, et al. A pneumonia outbreak associated with a new coronavirus of probable bat origin. Nature 2020;579(7798):270-273

4 de Wit E, van Doremalen N, Falzarano D, Munster VJ. SARS and MERS: recent insights into emerging coronaviruses. Nat Rev Microbiol 2016;14(8):523-534 
5 Velavan TP, Meyer CG. The COVID-19 epidemic. Trop Med Int Health 2020;25(3):278-280

6 Ijaz MK, Brunner AH, Sattar SA, Nair RC, Johnson-Lussenburg CM. Survival characteristics of airborne human coronavirus 229E. J Gen Virol 1985;66(Pt 12):2743-2748

7 Linton NM, Kobayashi T, Yang Y, et al. Incubation period and other epidemiological characteristics of 2019 novel coronavirus infections with right truncation: a statistical analysis of publicly available case data. J Clin Med 2020;9(2):538

8 Mattiuzzi C, Lippi G. Which lessons shall we learn from the 2019 novel coronavirus outbreak?. Ann Transl Med 2020; $8(3): 48$

9 Wang C, Horby PW, Hayden FG, Gao GF. A novel coronavirus outbreak of global health concern. Lancet 2020;395(10223): 470-473

10 Chen N, Zhou M, Dong X, et al. Epidemiological and clinical characteristics of 99 cases of 2019 novel coronavirus pneumonia in Wuhan, China: a descriptive study. Lancet 2020;395(10223): 507-513 doi:10.1016/S0140-6736(20)30211-7

11 Cai J, Sun W, Huang J, Gamber M, Wu J, He G. Indirect virus transmission in cluster of COVID-19 cases, Wenzhou, China, 2020. Emerg Infect Dis 2020;26(6):1343-1345

12 Bai Y, Yao L, Wei T, et al. Presumed asymptomatic carrier transmission of COVID-19. JAMA 2020;323(14):1406

13 Wang T, Du Z, Zhu F, et al. Comorbidities and multi-organ injuries in the treatment of COVID-19. Lancet 2020;395(10228):e52

14 Xie J, Tong Z, Guan X, Du B, Qiu H. Clinical characteristics of patients who died of coronavirus disease 2019 in China. JAMA Netw Open 2020;3(4):e205619

15 Ahmed N, Maqsood A, Abduljabbar T, Vohra F. Tobacco smoking a potential risk factor in transmission of COVID-19 infection. Pak J Med Sci 2020;36(COVID19-S4) :S104-S107

16 Cowling BJ, Aiello AE. Public health measures to slow community spread of coronavirus disease 2019. J Infect Dis 2020;221(11):1749-1751

17 Xie X, Xue Q, Zhou Y, et al. Mental health status among children in home confinement during the coronavirus disease 2019 outbreak in Hubei Province, China. JAMA Pediatr 2020;174(9):898-900 doi:10.1001/jamapediatrics.2020.1619

18 A Maqsood, Ruqaya, S Sarfaraz, AB Irfan, A Faisal HF. Healthcare workers knowledge, practices and stress level amid COVID-19 pandemic. Pakistan Armed Forces Med J 2020;70(1):244-250

19 Kroenke K, Spitzer RL, Williams JBW. The PHQ-9: validity of a brief depression severity measure. J Gen Intern Med 2001;16(9):606-613

20 Spitzer RL, Kroenke K, Williams JBW, Löwe B. A brief measure for assessing generalized anxiety disorder: the GAD-7. Arch Intern Med 2006;166(10):1092-1097

21 Özdin S, Bayrak Özdin Ş. Levels and predictors of anxiety, depression and health anxiety during COVID-19 pandemic in Turkish society: the importance of gender. Int J Soc Psychiatry 2020;66(5):504-511

22 Meng H, Xu Y, Dai J, Zhang Y, Liu B, Yang H. Analyze the psychological impact of COVID-19 among the elderly population in China and make corresponding suggestions. Psychiatry Res 2020;289:112983

23 Simon AK, Bhumika TV, Nair NS. Does atraumatic restorative treatment reduce dental anxiety in children? A systematic review and meta-analysis. Eur J Dent 2015;9(2):304-309

24 Ahmed MA, Jouhar R, Ahmed N, et al. Fear and practice modifications among dentists to combat novel coronavirus disease (COVID-19) outbreak. Int J Environ Res Public Health 2020;17(8):2821

25 De Sousa A, Mohandas E, Javed A. Psychological interventions during COVID-19: challenges for low and middle income countries. Asian J Psychiatr 2020;51:102128

26 'Ban Imposed on face mask hoarding, profiteering'. The News website. Updated March 10, 2020. Available at: https://www. thenews.com.pk/print/626676-ban-imposed-on-face-maskhoarding-profiteering. Accessed May 21, 2020

27 Qureshi Z. COVID-19: 3-year jail term for hoarders of consumer items in Pakistan. Gulf News website. Updated April 18, 2020. Available at: https://gulfnews.com/world/asia/pakistan/covid-19-3-year-jail-term-for-hoarders-of-consumeritems-in-pakistan-1.71047972. Accessed May 21, 2020

28 Garfin DR, Silver RC, Holman EA. The novel coronavirus (COVID-2019) outbreak: Amplification of public health consequences by media exposure. Health Psychol 2020;39(5): 355-357

29 Tasnim S, Hossain MM, Mazumder H. Impact of rumors or misinformation on coronavirus disease (COVID-19) in social media. J Prev Med Public Health 2020;53(3):171-174

30 Barro R, Ursúa J, Weng J. The coronavirus and the great influenza pandemic: Lessons from the "Spanish Flu" for the coronavirus's potential effects on mortality and economic activity. NBER Working Papers 26866, National Bureau of Economic Research, Inc. [Internet]. Cambridge, MA; 2020 Mar. Available at: http://www.nber.org/papers/w26866.pdf.

31 Li W, Yang Y, Liu Z-H, et al. Progression of mental health services during the COVID-19 outbreak in China. Int J Biol Sci 2020;16(10):1732-1738

32 Asmundson GJ, Taylor S. Coronaphobia: fear and the 2019-nCoV outbreak. J Anxiety Disord 2020;70:102196

33 Carvalho PMM, Moreira MM, de Oliveira MNA, Landim JMM, Neto MLR. The psychiatric impact of the novel coronavirus outbreak. Psychiatry Res 2020;286:112902

34 Said OB, Razumova S, Velichko E, Tikhonova S, Barakat H. Evaluation of the changes of salivary $\mathrm{pH}$ among dental students depending on their anxiety level. Eur J Dent 2020 14(4):605-612

35 Xiang Y-T, Yang Y, Li W, et al. Timely mental health care for the 2019 novel coronavirus outbreak is urgently needed. Lancet Psychiatry 2020;7(3):228-229

36 Maunder R, Hunter J, Vincent L, et al. The immediate psychological and occupational impact of the 2003 SARS outbreak in a teaching hospital. Can Med Assoc J 2003;168(10):1245-1251 